\title{
Algunas cuestiones sobre responsabilidad en el contrato de concesión de obra pública
}

\author{
Pedro Luis Serrera Contreras
}

Abogado del Estado

\begin{abstract}
SUMARIO: I.- LA ASUNCIÓN DEL RIESGO. II.- RESPONSABILIDAD POR PROYECTO O POR MEJORAS. III.- LA RESPONSABILIDAD DEL CONCESIONARIO. IV.- GUANDO APARECE EL SUBCONTRATISTA. V.- NATURALEZA DE LA RELAGIÓN DEL CONTRATISTA CON TERCEROS. VI.- SI CABE LA ACCIÓN DIRECTA EN ESTE CONTRATO ADMINISTRATIVO. VII.- LA ACCIÓN DIRECTA EN CONTRATO PRIVADO.
\end{abstract}

\section{LA ASUNCIÓN DEL RIESGO}

En el BOE de 24 de Mayo de 2003 se publica la Ley 13 de ese año de fecha 23 de Mayo por la que se aprueba la regulación del contrato de concesión de obra pública, la cual se inserta como nuevo título, el V, en el Libro III, de la Ley de Contratos de las Administraciones Públicas. La nueva normativa se desarrolla en los arts. 220 al 266, ambos inclusive. Y, como figuran al final del texto legal, no han supuesto ningún problema de cambio de numeración en los artículos ni introducción de números bises, lo cual ciertamente es de agradecer.

Uno de los principios que preside la nueva regulación, y así lo expresa la Exposición de Motivos, es que el contratista asuma el riesgo en la concesión. Por eso ya en el primer artículo del título añadido, que es el 220, en su apartado 2 proclama que la construcción y explotación de las obras públicas objeto de concesión se efectuarán a riesgo y ventura del concesionario, quien asumirá los riesgos económicos derivados de su ejecución y explotación. Luego el art. 239, que se inserta en el capítulo II sección $3^{3}$ que versa sobre la ejecución de las obras, reitera en el apartado 1 que las obras se construirán a riesgo y ventura del concesionario.

\section{RESPONSABILIDAD POR PROYEGTO O POR MEJORAS}

Pero veamos ya los supuestos de responsabilidad. Y el primero aparece cuando el concesionario redacta el proyecto. Efectivamente el art. 229, que 
después veremos, contempla el supuesto de que, según los términos de la concesión, al concesionario le corresponda presentar el proyecto. Y es que el art. 220 en el apartado 3 prevé que la Administración podrá establecer que el concesionario redacte el proyecto de construcción de las obras. Y añade que en tal supuesto la aprobación del proyecto corresponderá a la Administración concedente y formará parte del contrato de concesión. Pues bien, en este supuesto puede surgir responsabilidad a cargo del contratista como enseguida veremos.

A ese supuesto se equipara en alguna forma el de que el concesionario haya introducido mejoras en lo proyectado por la Administración. El art. 228 apartado 5 lo prevé expresamente para el anteproyecto, en el que, cuando el pliego de cláusulas lo autorice, el licitador podrá introducir las mejoras que estime convenientes. Y eso mismo establece el art. 229 apartado 3 para las mejoras en el proyecto.

Pues bien, en estos casos de mejora cabe darse una posible responsabilidad de quien las introdujo, puesto que en cierta forma en cuanto a ellas es como si el concesionario hubiera redactado el oportuno proyecto. Pero veamos ya esa responsabilidad.

La establece claramente el apartado 5 del art. 229. "El concesionario responderá de los daños derivados de los defectos del proyecto cuando, según los términos de la concesión, le corresponda su presentación o haya introducido mejoras en el propuesto por la Administración. La responsabilidad se extenderá también a los daños debidos a defectos de los proyectos para la conservación y explotación de la obra pública”.

Esta responsabilidad de quien redactó el proyecto es en realidad la que preveía el art. 219 de la Ley cuando regulaba el contrato de elaboración de proyectos de obras. Y en el apartado 1 establecía que el contratista respondería de los daños y perjuicios que durante la ejecución o explotación de las obras se causen por defectos e insuficiencias técnicas del proyecto o por los errores materiales, omisiones e infracciones de preceptos legales o reglamentarios, imputables al mismo. Esto es pues lo que implica aquella responsabilidad del 229.

Pero el citado art. 219 no terminaba ahí. Porque en el apartado 2 añadía que la indemnización exigible al contratista alcanzaría el $50 \%$ de los daños y perjuicios causados (siendo el otro $50 \%$ a cargo de la Administración), hasta un límite máximo de cinco veces el precio pactado por el proyecto, y será exi- 
gible dentro del término de 10 años, contados desde que la Administración recibió el proyecto.

No parece que deba haber duda sobre que tales limitaciones se aplican en el supuesto del art. 229. Porque en definitiva el contratista o concesionario redacta un proyecto (que es el supuesto específico del art. 219). Y para las mejoras ya hemos dicho que vienen a equivaler a un proyecto parcial.

Por tanto, debe ser aplicable el reparto al 50\% de los costes por indemnización, pues en definitiva la Administración al final hubo de dar por buenos tales proyectos o tales mejoras. Y lo mismo ha de decirse del plazo temporal de los 10 años. Mantener más allá su responsabilidad podría ser desproporcionado. En suma esto se parece a la responsabilidad decenal que para las construcciones de inmuebles establece nuestro Código Civil.

En cambio plantea más dificultad el tope del quíntuplo de lo pagado por la realización del proyecto. Porque aquí la confección de éste no se remunera con una determinada cantidad, sino que queda embebida en lo que el concesionario obtendrá en la explotación de la obra pública.

No obstante, el tope tiene una razón fundada, para no hacer recaer responsabilidades que pueden ser inalcanzables. Por ello una interpretación analógica del art. 219 al caso del 229 habría de llevar a calcular el importe que hubiera supuesto la redacción de ese proyecto ( o de su mejora), bien por los propios datos que figuren en el expediente de contratación (estudios previos que la Administración hiciera), o por aplicación de las tarifas que para esos estudios existan en los correspondientes colegios profesionales o incluso en la propia Administración.

\section{LA RESPONSABILIDAD DEL CONGESIONARIO}

Pasamos ya al supuesto más genuino y normal de responsabilidad del concesionario de obra pública. Viene recogido en el art. 243 de la Ley bajo la rúbrica de obligaciones del concesionario. Entre ellas en la letra e) figura ésta: "Indemnizar los daños que se ocasionen a terceros por causa de la ejecución de las obras o de su explotación, cuando le sean imputables de acuerdo con el art. 97 de esta Ley”. Aquí sí que hay una referencia expresa al artículo pertinente.

En efecto, dicho art. 97, aplicable a los distintos contratos, establece en el apartado 1 que "será obligación del contratista indemnizar todos los daños y per- 
juicios que se causen a terceros como consecuencia de las operaciones que requiera la ejecución del contrato"; y esto es aplicable al contrato que nos ocupa.

Después el apartado 2 establece las exclusiones. "Cuando tales daños y perjuicios hayan sido ocasionados como consecuencia inmediata y directa de una orden de la Administración, será ésta responsable dentro de los límites señalados en las leyes. También será la Administración responsable de los daños que se causen a terceros como consecuencia de los vicios del proyecto elaborado por ella misma en el contrato de obras o en el de suministro de fabricación”.

Es claro que cuando el daño se derive de una orden de la Administración será ésta quien responda, también en el contrato de concesión de obra pública. Y lo mismo cabe entender para cuando es ella la que elabora el proyecto. En primer lugar, si el apartado 2 del art. 97 no menciona al contrato de concesión de obra pública es porque el mismo se ha introducido posteriormente a redactarse tal artículo. Y de otro lado, en la nueva figura también es esencial el concepto de obra pública, cual expresa la exposición de motivos de la reciente ley. Es más, en el texto inicial de la Ley de Contratos había una embrionaria regulación del contrato de concesión de obra pública en los arts. 130 y ss. Pero como éstos estaban dentro del título dedicado al contrato de obras, es claro que la mención del art. 97 apartado 2 abarcaba a las distintas modalidades previstas en ese título.

La responsabilidad del concesionario que se ha indicado, en su principio general y en sus exclusiones, es independiente de la labor de inspección que a la Administración corresponda. La misma queda reflejada en el art. 249 letra f) cuando enuncia como derecho de aquélla: Vigilar y controlar el cumplimiento de las obligaciones del concesionario, a cuyo efecto podrá inspeccionar al servicio, sus obras, instalaciones, locales... Facultad parecida es la que, dentro del contrato de gestión del servicio público, se encomienda a la Administración en el art. 155 apartado 3 de la Ley, o sea la de conservar los poderes de policía necesarios par asegurar la buena marcha de los servicios. Todo lo cual no excluye la responsabilidad del concesionario de obra pública en los términos anteriormente reseñados.

\section{CUANDO APARECE EL SUBCONTRATISTA}

Tras el examen de la responsabilidad del concesionario, procede abordar la que se plantea cuando aparece la figura del subcontratista. La nueva Ley ya 
se refiere al mismo en el art. 236, al tratar de la ejecución de las obras, donde establece que la que corresponde al concesionario podrá ser contratada en todo o en parte con terceros, de acuerdo con lo dispuesto en esta Ley y en el pliego de cláusulas particulares.

Es más, en el art. 237 se prevé que en el contrato de concesión de obras públicas la Administración podrá imponer al concesionario que subcontrate con terceros un porcentaje de los contratos de obras objeto de la concesión que represente al menos un $30 \%$ del valor total de dichas obras.

Si el concesionario va a contratar la obra en todo o en parte, deberá indicarlo al órgano de contratación, aportando los datos que éste requiera. Pero el art. 236 apartado 3 establece que corresponde al órgano de contratación el control de la ejecución de la obra en los términos que se establezcan en el correspondiente pliego de prescripciones técnicas.

Con independencia de ello, el art. 238 previene en el apartado 1 que corresponde al concesionario el control de la ejecución de las obras que contrate con terceros. Ese control debe ajustarse al plan que elabore el concesionario y resulte aprobado por el órgano de contratación. Éste podrá girar a las obras las visitas de inspección que crea oportunas.

Pero en cuanto a la responsabilidad por esas obras que ejecuten terceros, viene claramente establecida en el apartado 2 de ese art. 238: "El concesionario será responsable ante el órgano de contratación de las consecuencias derivadas de la ejecución o resolución de los contratos que celebre con terceros y responsable asimismo único frente a éstos de las mismas consecuencias".

Ello en definitiva es un traslado de lo que con carácter general establece el art. 1.596 del Cc. para el contrato de arrendamiento de obra. O sea que el contratista es responsable del trabajo ejecutado por las personas que ocupase en las obras. Precepto que en principio es aplicable tanto a los propios operarios como al subcontratista.

Eso mismo lo ha recogido la Ley de Contratos en el art. 115 relativo a la subcontratación. Conforme a su apartado 3, "los subcontratistas quedarán obligados sólo ante el contratista principal que asumirá, por tanto, la total responsabilidad de la ejecución del contrato frente a la Administración, con arreglo estricto a los pliegos de cláusulas administrativas particulares y a los términos del contrato". Y es que con carácter general el art. 143, relativo a la ejecución del contrato de obras, prescribe que durante el desarrollo de éstas y has- 
ta que se cumpla el plazo de garantía, el contratista es responsable de los defectos que en la construcción puedan advertirse.

Tenemos por tanto que en esos casos de subcontrato es el contratista el que asume la responsabilidad. Y hay que entender que por los daños a terceros o aún a la propia Administración. Lo cual no impide que sea esta última la que responda si se está en los casos de exclusión del art. 97 de la Ley (orden expresa o vicio del proyecto). A su vez nada impide que cuando el contratista haya respondido, el mismo pueda repetir frente al subcontratista si fue éste el verdadero causante de aquel daño.

\section{NATURALEZA DE LA RELACIÓN DEL CONTRATISTA CON TERGEROS}

Hay que sentar que el contrato de concesión de obra pública es de los contratos administrativos que especialmente se incluye en la ley reguladora de ellos. Por tanto, en aquél la Administración tendrá las prerrogativas que con carácter general enuncia el artículo 59 de la Ley.

Por ello, el art. 7 concluye en el apartado 3 que el orden jurisdiccional contencioso-administrativo será el competente para resolver las controversias que surjan entre las partes en los contratos administrativos. Lo remacha el art. 60 que, tras haberse tratado en el anterior de las prerrogativas de la Administración, añade en el apartado 1 que contra los acuerdos que pongan fin a la vía administrativa procederá el recurso contencioso-administrativo.

En cambio, para los contratos de suministro que el contratista concierte con terceros y para la subcontratación que haga, el último inciso del art. 116 de la Ley establece que los mismos tendrán en todo caso naturaleza privada. Lo confirma la Sentencia de la Sala Primera del Tribunal Supremo de 9 de Julio de 2.003 (RA 4619).

Esto es lógico pues al fin y al cabo se trata de una relación entre dos particulares. Si acaso y desde el punto de vista sistemático, debe advertirse que tal prescripción hubiera encajado mejor al final del art. 115 (que regula la subcontratación y que en el apartado 2 c) se refiere a los suministros), y no en el art. 116 que en realidad se dedica a los requisitos de tales subcontratos y suministros.

$\mathrm{Al}$ tener naturaleza privada la relación entre el contratista y aquellos terceros, es claro que de esos contratos entiende el orden civil. Porque, si el art. 
9 apartado 3 de la Ley así lo establece para los contratos privados que concierte la Administración, a fortiori entenderán de esas controversias los tribunales civiles cuando las dos partes sean privadas.

\section{SI CABE LA ACCIÓN DIRECTA EN ESTE CONTRATO ADMI- NISTRATIVO}

Un problema que se plantea en el caso de la subcontratación es el de si sería aplicable en los contratos administrativos la acción directa que el art. 1597 del Cc prevé para los que pusieron trabajo o materiales. Según tal precepto: "Los que ponen su trabajo y materiales en una obra ajustada alzadamente por el contratista, no tienen acción contra el dueño de ella sino hasta la cantidad que éste adeude a aquél cuando se hace la reclamación.”.

Es una típica acción para evitar el enriquecimiento injusto que se daría en el principal, a costa de los suministradores, por medio del contratista. Se ha destacado pues que el fundamento último de tal precepto está en la equidad. Para reforzar la postura de tales suministradores la Sentencia de la Sala Primera del Tribunal Supremo de 7 de Febrero de 1.968 establece una responsabilidad solidaria frente a ellos del dueño de la obra y del contratista.

Pero fue la decisiva Sentencia de esa Sala de 29 de Junio de 1.936 (RA 1491) la que, extendiéndose en el fundamento de aquel precepto, lo declaró aplicable al caso del subcontratista, aunque literalmente no apareciera previsto en el art. 1.597. En esa sentencia se viene a calificar tal acción directa como una especie de subrogación personal en el crédito del contratista. A su vez esa acción encuentra apoyo en el principio de que quien es deudor de mi deudor lo es también de mí.

Supuesto lo anterior, no parece que tal actio in rem verso pueda aplicarse en los contratos administrativos; aunque en ellos la obra se haya concertado a tanto alzado. Porque la propia Ley de Contratos regula detalladamente los requisitos que han de darse para que quepa la subcontratación de la obra (art. 115); y porque después previene con todo rigor la forma y condiciones de los pagos que el contratista ha de hacer a esos suministradores (art. 116). Con una regulación tan detallada no cabe entender que se esté ante laguna alguna para introducir supletoriamente aquel precepto del Código Civil.

Es más, todavía podrá mantenerse tal aplicación cuando las certificaciones de las obras públicas se declaran absolutamente inembargables (como una 
garantía de la oportuna conclusión de las obras públicas). Pero esa no es la situación actual.

En efecto, hoy el art. 99 de la Ley, relativo al pago del precio, establece en el apartado 7 que los abonos a cuenta (consecuencia de las certificaciones) sólo podrán ser embargados en los siguientes supuestos: a) Para el pago de los salarios devengados por el personal del contratista en la ejecución del contrato y de las cuotas sociales derivadas de las mismas. b) Para el pago de las obligaciones contraídas por el contratista con los subcontratistas y suministradores referidas a la ejecución del contrato.

Por tanto, es así como esos interesados podrán perseguir el cobro de lo que les deba el contratista con el que se relacionaron. No tiene pues encaje el art. 1.597. Además, falla ese enriquecimiento injusto que tal norma trata de evitar, pues la Administración no va a eludir el cumplimiento de la obligación de pago que le corresponde, ni en principio cabe presumir una insolvencia de la misma que acarree un perjuicio definitivo. Ahí están las certificaciones de obras que suponen evidente garantía.

\section{LA ACGIÓN DIRECTA EN CONTRATO PRIVADO}

Ya que hemos tratado de la acción directa del subcontratista y hemos negado su aplicación en los contratos administrativos, y entre ellos en el de concesión de obra pública, donde esos terceros aparte del contratante principal pueden aparecer con tanta frecuencia, procede preguntar si aquella acción se dará en los contratos que se sujetan al derecho privado y que pueden concertar ciertas entidades relacionadas con la Administración.

En principio la respuesta habría de ser positiva porque el art. 9 apartado 1 de la Ley de Contratos establece para los que sean privados que en cuanto a sus efectos y extinción se regirán por las normas de derecho privado. Dentro de las cuales está el art. 1.597 del Código Civil.

Mas también el art. 4 de aquella Ley sienta el principio de libertad de pactos, conforme al cual la Administración podrá fijar los pactos y condiciones que tenga por conveniente, siempre que no sean contrarios al interés público, al ordenamiento jurídico o a los principios de buena administración. Y si para aquellos contratos privados se pacta una remisión amplia a las normas de la Ley de Contratos, y en concreto a todo lo que se refiere a la subcontratación, habría que entender que tampoco procede la acción directa del subcontratis- 
ta, por las mismas razones que antes expusimos para los contratos administrativos.

Ahora bien, puede ocurrir que en ese contrato privado no se hayan establecido estipulaciones especiales para el caso de la subcontratación. Parece que entonces, si se aplica el derecho privado, dentro del mismo podría entrar aquel art. 1.597.

Es verdad que si cabe embargar las certificaciones de obras, en pleito que el tercero siguiera contra el contratista, podría no serle necesaria aquella acción directa frente a la entidad dueña de la obra. Pero tampoco cabe descartar que por diversas razones, aun atendibles, aquel subcontratista prefiera demandar al principal. Aunque algunas razones pudieran esgrimirse en contra de esa posibilidad, no parece que quepa excluir de plano aquella opción por la reclamación directa.

Ésta presupone que el dueño de la obra deba aun parte del importe de ésta al contratista. Pues bien, en ese caso, ante la reclamación que el subcontratista hiciera al principal, cabría decir que estamos ante la figura del litigio entre pretendientes que ha estudiado perfectamente la doctrina procesal. Porque en última instancia a la entidad dueña de la obra le viene a resultar indiferente que lo que debe y ha de pagar lo sea a una persona o a otra, siempre que ella quede liberada por ese pago.

Como expone Montero Aroca, en su Derecho Jurisdiccional, tomo II sobre el proceso civil, $10^{\text {a }}$ edición en 2.001, si la entidad principal es demandada por el subcontratista, "puede llamar al procedimiento a los otros pretendientes (el contratista), los cuales si intervienen darán lugar a una intervención principal, aunque cabe la extromisión del demandado, el cual deberá depositar previamente lo reclamado”.

Si se tratara de una entidad pública, posiblemente bastaría con el ofrecimiento en firme de pagar a quien resultara victorioso; pues por la solvencia que en aquélla se supone juega la exención de prestar ese depósito o consignación.

El procedimiento para aquella llamada al tercero (el contratista) es el que hoy establece el art. 14 de la nueva LEC. Tras oír al demandante (el subcontratista), el tribunal acordará el emplazamiento de aquel tercero. Se traba así el verdadero litigio entre pretendientes, pues la entidad demandada en todo caso habría de pagar el importe de obra realizada y aun no abonada. 
Al supuesto también alude la última regla del art. 14 de la LEC, en relación con el art. 18 de ésta. Porque en efecto, puede suceder que haya una sucesión en la parte del demandado y continuar así el litigio entre los otros dos interesados. El supuesto quedaría enormemente facilitado si ese demandado, cual indicaba Montero, deposita o consigna el importe reclamado, mostrando así su expresa voluntad de pagar a quien mejor derecho tuviera. 